\title{
CICLO DE PRODUÇÃO E DEMANDA TÉRMICA DE CLONES DA VIDEIRA 'CONCORD' SOBRE DIFERENTES PORTA-ENXERTOS ${ }^{1}$
}

\author{
ROGÉRIO DE SÁ BORGES 2 , SERGIO RUFFO ROBERTO ${ }^{3}$, FABIO YAMASHITA ${ }^{4}$, \\ ADRIANE MARINHO DE ASSIS ${ }^{5}$, LILIAN YUKARI YAMAMOTO ${ }^{6}$
}

RESUMO- O objetivo do trabalho foi determinar a duração do ciclo de produção e a necessidade térmica de seis clones de 'Concord' sobre três porta-enxertos no norte do Paraná. Foram avaliados os clones '22', '28', '49', '202', '211' e '225', obtidos pela Embrapa Uva e Vinho, e enxertados sobre os porta-enxertos 'IAC 766', 'IAC 572' e '420-A'. O trabalho foi realizado em área experimental pertencente ao Centro Tecnológico da COROL - Cooperativa Agroindustrial, localizado no município de Rolândia-PR. O experimento foi realizado em esquema fatorial (6 clones x 3 porta-enxertos), em delineamento inteiramente casualizado, com cinco repetições. As plantas foram conduzidas em sistema de latada, no espaçamento de 4,0 $\mathrm{m}$ x 2,0 m, e as avaliações foram realizadas nas safras de 2009/2010 e 2010/2011. Verificou-se que dentre os clones de 'Concord' avaliados, o '202' apresenta a menor duração do ciclo entre a poda e a colheita, sendo portanto o mais precoce. Dentre os porta-enxertos, o '420-A' induz a maior taxa de acúmulo diário de sólidos solúveis do mosto, proporcionando redução do ciclo total e da demanda térmica dos clones de 'Concord', enquanto o 'IAC 572' induz a menor taxa, promovendo aumento do ciclo e da demanda térmica dos clones.

Termos para indexação: acúmulo de SS, graus-dia, Vitis labrusca, porta-enxertos.

\section{PHENOLOGICAL CYCLE AND THERMAL DEMAND OF GRAPEVINE'S CLONES OF 'CONCORD' ON DIFFERENT ROOTSTOCKS}

\begin{abstract}
The aim of this study was to determine the duration of the production cycle and the thermal requirement of six clones of the 'Concord' grapevine, on three rootstocks, in the North of Paraná. The 'Concord' clones '22', '28', '49', '202', '211' and '225', obtained by Embrapa Grape and Wine, were evaluated grafted on '420-A', 'IAC 766' and 'IAC 572' rootstocks. The trial was carried out in an experimental vineyard located at the Technology Center of COROL Cooperative, in Rolândia, PR. A completely randomized design was used as statistical model, arranged in a factorial system (six clones $\mathrm{x}$ three rootstocks) with five replications. The grapevines were trained in a overhead trellis system, spaced at $4.0 \times 2.0 \mathrm{~m}$. The evaluations were performed during the harvest of 2009/2010 and 2010/2011. It was verified that '202' is the earliest 'Concord' clone, by showing the lowest cycle duration from pruning to harvest. Among the rootstocks, the ' 420 -A' induces the highest daily rate accumulation of solid soluble, reducing the total cycle and the thermal demand, while the 'IAC 572' induces the lowest rate, increasing the cycle and the thermal demand of the clones.

Index terms: SS accumulation, degree-days, Vitis labrusca, rootstocks.
\end{abstract}

\footnotetext{
'(Trabalho 384-13). Recebido em: 08-10-2013. Aceito para publicação em: 16-04-2014.

${ }^{2}$ Engenheiro Agrônomo, Dr, Embrapa Produtos e Mercado - Escritório de Londrina, Rod. Carlos João Strass, Acesso Orlando Amaral. CEP 86001-970, CP 231, Londrina, PR. e-mail: rogerio.borges@embrapa.br

${ }^{3}$ Engenheiro Agrônomo, Dr. Professor Associado, Departamento de Agronomia/Fitotecnia, Universidade Estadual de Londrina (UEL), Bolsista do CNPq. Rod. Celso Garcia Cid, PR 445, Km 380. CEP 86051-990, CP 6001, Londrina, PR. e-mail: sroberto@uel.br ${ }^{4}$ Engenheiro de Alimentos, Dr. Professor Associado, Departamento de Ciência e Tecnologia de Alimentos, Universidade Estadual de Londrina (UEL), Bolsista do CNPq. Rod. Celso Garcia Cid, PR 445, Km 380. CEP 86051-990, CP 6001, Londrina, PR. e-mail: fabioy@uel.br

${ }^{5}$ Engenheira Agrônoma, Dra. Professora Assistente, Departamento de Agronomia/Fitotecnia, Universidade Estadual de Londrina (UEL), Bolsista da Capes. Rod. Celso Garcia Cid, PR 445, Km 380. CEP 86051-990, CP 6001, Londrina, PR. e-mail: agroadri@ ig.com.br

${ }^{6}$ Engenheira Agrônoma, Doutoranda em Agronomia, Programa de Pós-Graduação do Centro de Ciências Agrárias (CCA), Universidade Estadual de Londrina (UEL), Rod. Celso Garcia Cid PR 445, Km 380. CEP 86051-990, CP 6001, Londrina-PR. Bolsista CNPq. e-mail: lilianyamamoto@yahoo.com.br
} 


\section{INTRODUÇÃO}

A Serra Gaúcha no Rio Grande do Sul sempre ocupou posição de destaque na produção brasileira de uvas destinadas à produção de suco (RIZZON; MIELE, 2012). No entanto, nos últimos anos, esta atividade também vem sendo explorada em outras regiões do País, como Rolândia (PR), Videira (SC), Santa Tereza (ES), Nova Mutum (MT), Itaberaí (GO) e até mesmo no Vale do São Francisco, na região Nordeste. As principais cultivares exploradas são de origem americana como: Isabel, Concord e Bordô (BORGES et al., 2013).

Embora a viticultura da região norte do Paraná seja caracterizada pela produção de uvas finas de mesa, nos últimos anos, tem havido grande busca por informações sobre o cultivo de uvas para processamento. Em função de projetos de produção de suco de uva implantados por grandes cooperativas da região, a uva rústica no norte do Estado apresentou um expressivo crescimento da área plantada (ROBERTO et al., 2004).

Todo vegetal necessita de uma quantidade constante de energia térmica para completar seu ciclo de desenvolvimento. Essa quantidade de energia é normalmente expressa em graus-dia (GD), que é a diferença entre a temperatura média ambiente e a temperatura-base (valor abaixo do qual não ocorre desenvolvimento) (SATO et al., 2008). O conhecimento das necessidades térmicas permite que o viticultor faça um planejamento da duração do ciclo de produção e a provável data de colheita, de acordo com os dados climáticos de cada região e a demanda térmica de cada variedade (TECCHIO et al., 2013).

A origem policlonal da videira favorece a ocorrência de mutações espontâneas que podem manifestar-se por meio de características distintas da cultivar original. A seleção clonal consiste no trabalho de identificar estas diferenças visando à obtenção de clones com características de interesse, como maior produtividade, ciclo diferenciado, melhor qualidade ou resistência a pragas (REGINA, 2004).

Dentre as videiras destinadas à elaboração de suco que vêm sendo cultivadas no norte do Paraná, a 'Concord' tem-se destacado pelas boas características de aroma e sabor que confere ao suco. A Embrapa Uva e Vinho iniciou, em 1992, um trabalho de seleção clonal da cultivar Concord por meio da prospecção de plantas em 21 vinhedos de 10 municípios da região de Caxias do Sul (RS), onde foram selecionadas 234 plantas de 'Concord' que foram propagadas em coleção clonal na Embrapa, originando diversos clones com características diversas, os quais, a partir daí, vêm sendo avaliados em diversas regiões. Em
2002, com o objetivo de identificar alguns desses clones que apresentassem vantagens comparativas para as condições do norte do Paraná, os clones '22', '28', '49', '202', '211' e '225' foram implantados para avaliação no Centro Tecnológico da COROL - Cooperativa Agroindustrial em Rolândia-PR (CAMARGO et al., 2000).

A utilização de porta-enxertos para a propagação da videira é prática comum entre viticultores de várias partes do mundo. Segundo Dias et al. (2012), a escolha do porta-enxerto pode afetar diretamente a produtividade, o ciclo e a absorção de nutrientes, além de influenciar nas características químicas da baga.

Dessa forma, o presente trabalho teve como objetivo determinar a duração do ciclo de produção e a necessidade térmica desses seis clones de 'Concord' sobre os porta-enxertos '420-A', 'IAC 572' e 'IAC 766 ' no norte do Paraná.

\section{MATERIAL E MÉTODOS}

O trabalho foi realizado em área experimental pertencente ao Centro Tecnológico da COROL Cooperativa Agroindustrial, localizado no município de Rolândia-PR, em Latossolo Vermelho Distroférrico, textura média argilosa (EMBRAPA, 1999). As coordenadas geográficas são $23^{\circ} 27^{\prime} \mathrm{S}, 51^{\circ} 47^{\prime} \mathrm{O}$, com $600 \mathrm{~m}$ de altitude, precipitação média anual de 1.610 mm e temperatura média anual de $21,2^{\circ} \mathrm{C}$.

Foram avaliados seis clones da videira 'Concord' (Vitis labrusca): '22', '28', '49', '202', '211'e '225', selecionados pela Embrapa Uva e Vinho (CAMARGO et al., 2000), sobre três portas-enxertos: 'IAC 766' (Riparia do Traviú x Vitis caribaea), 'IAC 572' (V. caribaea $\mathrm{x}$ (Vitis riparia $\mathrm{x}$ Vitis rupestris 101-14)) e '420-A' (Vitis berlandieri x V. riparia).

As plantas foram conduzidas em sistema de latada, no espaçamento de $4,0 \mathrm{~m}$ entre linhas e $2,0 \mathrm{~m}$ entre plantas. As avaliações foram realizadas nas safras de 2009/2010 e 2010/2011. As podas de frutificação foram realizadas em setembro de 2009 e 2010, logo após o fim do período hibernal. Foram deixadas duas gemas por esporão e, em seguida, procedeu-se à aplicação do regulador de crescimento cianamida hidrogenada $\left(\right.$ Dormex $^{\circledR}$ ) a $2,5 \%$ para a quebra de dormência e a obtenção de brotação uniforme.

$\mathrm{O}$ experimento foi realizado em esquema fatorial ( 6 clones $x 3$ porta-enxertos), em delineamento inteiramente casualizado, com cinco repetições e uma planta por parcela.

Para a determinação da duração em dias do ciclo de produção das diferentes combinações entre 
clones e porta-enxertos, compreendido entre a poda e a colheita, foram realizadas observações visuais em cinco esporões marcados por parcela.

Para a caracterização das exigências térmicas, foi utilizado o somatório de graus-dia (GD) desde a poda até a colheita, empregando-se dados climáticos do Instituto Agronômico do Paraná - IAPAR, para o município de Rolândia, segundo as seguintes equações propostas por Villa Nova (1972):

a) $\mathrm{GD}=(\mathrm{Tm}-\mathrm{Tb})+(\mathrm{TM}-\mathrm{Tm}) / 2$, para $\mathrm{Tm}>\mathrm{Tb}$;

b) $\mathrm{GD}=(\mathrm{TM}-\mathrm{Tb}) 2 / 2(\mathrm{TM}-\mathrm{Tm})$, para $\mathrm{Tm}<\mathrm{Tb}$, e

c) $\mathrm{GD}=0$, para $\mathrm{Tb}>\mathrm{TM}$.

em que:

$\mathrm{GD}=$ graus-dia;

$\mathrm{TM}=$ temperatura máxima diária $\left({ }^{\circ} \mathrm{C}\right)$;

$\mathrm{Tm}=$ temperatura mínima diária $\left({ }^{\circ} \mathrm{C}\right)$;

$\mathrm{Tb}=$ temperatura-base $\left({ }^{\circ} \mathrm{C}\right)$;

Foi considerada a $\mathrm{Tb}=10^{\circ} \mathrm{C}$.

Os teores de sólidos solúveis (SS) foram avaliados a partir do início da maturação, caracterizado pelo início da mudança de cor, até a colheita. Foram coletadas 20 bagas de cada parcela que foram posteriormente analisadas no Laboratório de Análise de Frutas pertencente ao Centro de Ciências Agrárias da Universidade Estadual de Londrina-PR. Os valores obtidos de SS foram utilizados para o cálculo da taxa média diária de acúmulo de SS. A diferença entre o teor de SS final e inicial foi dividida pelo número de dias do início da maturação até a colheita, e as médias obtidas foram expressas em ${ }^{\circ}$ Brix.dia ${ }^{-1}$.

O teor de SS do mosto das uvas foi determinado em refratômetro digital de bancada com compensação automática de temperatura por meio do esmagamento e posterior filtragem das amostras em algodão.

Os resultados da duração do ciclo de produção, soma térmica total e taxa média diária de acúmulo de SS foram submetidos à análise de variância, e as médias, comparadas pelo teste de Tukey, a 5\% de probabilidade.

\section{RESULTADOS E DISCUSSÃO}

Para a duração do ciclo de produção, foi verificada interação significativa entre os clones de 'Concord' e os porta-enxertos. Comparando-se a duração total dos ciclos entre as duas safras avaliadas, verificou-se diferença significativa $(\mathrm{P}<0,05)$ para todas as combinações entre os clones de 'Concord' e os porta-enxertos. Na primeira safra, todos os tratamentos apresentaram ciclo mais curto do que na segunda safra (Tabela 1).
As diferenças na duração dos ciclos das duas safras devem-se às temperaturas mais elevadas, principalmente as mínimas e médias ocorridas no início do ciclo da primeira safra e durante os meses de novembro e dezembro de 2009 (Figura 1). Segundo Brighenti et al. (2013), a temperatura influencia diretamente no desenvolvimento vegetativo das videiras, podendo reduzir ou ampliar o ciclo de produção.

Outro aspecto que também pode ter contribuído para acelerar o início do ciclo vegetativo da primeira safra, refere-se ao bom suprimento de água no solo no momento da poda, em função do regime de chuvas desse ano. Na safra de 2009/2010, foi verificada maior disponibilidade de água no solo que pode ter promovido uma brotação mais rápida das plantas. Na segunda safra, por ocasião da poda no início de setembro, o solo apresentava déficit hídrico após um período seco, característico do inverno nesta região. De acordo com Pedro Júnior e Sentelhas (2003), a necessidade hídrica média da videira para a brotação é de $96 \mathrm{~mm}$ (Figura 2). Com relação aos porta-enxertos, verifica-se que, para as duas safras, o '420-A' apresentou tendência em reduzir o ciclo de produção dos clones de 'Concord'. Da mesma forma, para a maioria dos tratamentos, a maior duração dos ciclos dos clones foi observada quando se utilizou o 'IAC 572', sendo o 'IAC 766' de comportamento intermediário. Jogaiah et al. (2013) descreveram o ' $420-\mathrm{A}$ ' como sendo o porta-enxerto mais eficiente na indução de precocidade na videira.

Na safra de 2009/2010, o menor ciclo foi verificado para a combinação entre o clone '202' sobre o ' 420 -A' (114,2 dias), e o mais longo, para o clone '49' sobre o 'IAC 572' (119,6 dias). Na safra seguinte, as mesmas combinações apresentaram novamente o menor e o maior ciclo total (117,6 e 132,4 dias, respectivamente). Mandelli et al. (2003) avaliaram o ciclo da cultivar Concord sobre o porta-enxerto '101-14 Mgt' durante nove safras, na região da Serra Gaúcha-RS, e verificaram ciclo médio de 149 dias. Da mesma forma, Anzanello et al., (2012) obtiveram, para esta cultivar sobre o mesmo porta-enxerto, ciclo de 167 dias com poda de inverno, na região de Eldorado do Sul-RS. Em Caldas-MG, Pereira et al. (2008) obtiveram ciclo total de 157 dias para a 'Concord', também sobre '101-14 Mgt'.

Segundo Pedro Júnior e Sentelhas (2003), as diferenças edafoclimáticas entre regiões, especialmente a temperatura do ar, exercem grande influência no ciclo total da videira. As diferenças entre os resultados obtidos neste trabalho, com os trabalhos citados, devem-se às diferenças nas temperaturas médias, uma vez que, no norte do Paraná, as 
temperaturas são superiores às do Rio Grande do Sul e do sul de Minas Gerais.

Ao se analisar os clones de 'Concord' dentro de cada porta-enxerto, verifica-se que as maiores variações estiveram ao redor de sete dias e ocorreram entre os clones '49' e '202' sobre o 'IAC 572' (132,4 e 125,1 dias, respectivamente) e os clones '22' e '28' sobre o 'IAC 766' (128,0 e 121,1 dias, respectivamente), todos na segunda safra. Essa diferença talvez não seja suficiente para caracterizálos como cultivares diferentes como ocorreu com o clone '30', obtido por seleção clonal no mesmo trabalho, que resultou nos clones avaliados neste trabalho. Este apresentou ciclo médio 15 dias mais precoce que a 'Concord' tradicional e foi registrado como nova cultivar denominada 'Concord Clone 30' (CAMARGO et al., 2000).

De qualquer forma, verifica-se tendência de precocidade do clone '202', que poderia ser potencializada com o uso de porta-enxertos como o '420-A', além de outras técnicas de manejo que igualmente poderiam favorecer a precocidade, como a escolha da exposição do vinhedo e do sistema de condução mais adequados para essa finalidade. A diferença de ciclo também poderia ser usada para o escalonamento da colheita.

Com relação à soma térmica, também foi verificada interação significativa entre as copas e os porta-enxertos (Tabela 2). Comparando-se os resultados das duas safras, foram verificadas diferenças significativas $(\mathrm{P}<0,05)$ entre os dois anos de avaliação, sendo as médias da safra de 2009/2010 superiores à safra seguinte. $\mathrm{O}$ conceito de graus-dia preconiza que a videira necessita de uma quantidade constante de energia para completar as diferentes fases de seu ciclo (PEDRO JÚNIOR; SENTELHAS, 2003). Entretanto, este conceito assume característica linear entre desenvolvimento da cultura e temperatura, não sendo considerado o efeito de outros fatores ambientais (PEZZOPANE et al., 2008).Assim, as diferenças encontradas entre as duas safras podem estar relacionadas a outros fatores climáticos além da temperatura, como, por exemplo, a radiação solar e a luminosidade.

De forma geral, os clones enxertados sobre o '420-A' apresentaram tendência em reduzir a demanda térmica total dos clones de 'Concord'. Da mesma forma, o 'IAC 572' induziu à copa maior exigência térmica.

A combinação do clone '202'/4420-A' apresentou as menores médias nas duas safras (1.511 e 1.441 GD para as safras de 2009/2010 e 2010/2011, respectivamente). A maior soma térmica na primeira safra foi observada para a combinação do clone
'28'/'IAC 572' (1.575 GD) e na segunda safra para a combinação do clone '49'/'IAC 572' (1.627 GD). Os valores foram superiores ao obtido por Mandelli et al. (2003), que foi de 1.362 GD; entretanto, estes autores consideraram o ciclo de produção a partir da brotação. Anzanello et al. (2008) obtiveram soma térmica total de 1.496,9 para 'Concord' sobre '10114 Mgt' em Eldorado do Sul (RS), semelhantes aos valores obtidos neste trabalho.

Para a taxa média de acúmulo diário de $\mathrm{SS}$, não foi verificada interação entre os clones de 'Concord' e os porta-enxertos (Tabela 3). Na safra de 2009/2010, a maior taxa foi obtida com o clone '202' $\left(0,314^{\circ}\right.$ Brix.dia $\left.{ }^{-1}\right)$, e a menor, com o clone '22' $\left(0,272{ }^{\circ}\right.$ Brix.dia $\left.^{-1}\right)$. Os demais clones apresentaram comportamento intermediário quanto à taxa de acúmulo de SS. Na safra de 2010/2011, observou-se a mesma tendência para os clones, com exceção do clone '49', que apresentou menor taxa nesta safra $\left(0,243^{\circ}\right.$ Brix.dia $\left.^{-1}\right)$, juntamente com o clone '22' $\left(0,245^{\circ}\right.$ Brix.dia $\left.{ }^{-1}\right)$. Os resultados obtidos para a duração do ciclo total podem ser relacionados às taxas diárias de acúmulo de SS, uma vez que maiores taxas aceleram a maturação, resultando no encurtamento do ciclo total. As maiores taxas de acúmulo diário de SS obtidas para o '202' permitem compreender a maior precocidade que este clone possui em relação aos demais.

Quanto às médias dos porta-enxertos para a taxa de acúmulo diário de $\mathrm{SS}$, nas duas safras avaliadas, o '420-A' induziu maiores médias aos clones de 'Concord', demonstrando maior potencial glucométrico. A tendência verificada deste portaenxerto em proporcionar maior precocidade aos clones de 'Concord' também se justifica pelos valores obtidos para sua taxa de acúmulo diário de $\mathrm{SS}$, pois, a taxas maiores, a maturação completase mais precocemente. Da mesma forma, as taxas apresentadas pelo 'IAC 572' também corroboram os dados obtidos para o ciclo total dos clones sobre ele enxertados, uma vez que suas taxas menores estariam relacionadas a um maior tempo de maturação. 
TABELA 1- Duração do ciclo de produção (dias) dos clones de videira 'Concord' sobre três porta-enxertos, nas safras de 2009/2010 e 2010/2011. Rolândia-PR.

\begin{tabular}{ccccccc}
\hline & \multicolumn{3}{c}{ Safra 2009/2010 } & \multicolumn{3}{c}{ Safra 2010/2011 } \\
\cline { 2 - 7 } Clones de Concord & $420-\mathrm{A}$ & IAC 572 & IAC 766 & $420-\mathrm{A}$ & IAC 572 & IAC 766 \\
\hline 22 & $115,7 \mathrm{abB}$ & $119,0 \mathrm{aA}$ & $117,6 \mathrm{aA}$ & $123,4 \mathrm{aB}$ & $127,2 \mathrm{bcdA}$ & $128,0 \mathrm{aA}$ \\
28 & $115,4 \mathrm{abC}$ & $119,4 \mathrm{aA}$ & $117,8 \mathrm{aB}$ & $121,0 \mathrm{aB}$ & $126,3 \mathrm{cdA}$ & $121,1 \mathrm{~dB}$ \\
49 & $116,0 \mathrm{abC}$ & $119,6 \mathrm{aA}$ & $118,0 \mathrm{aB}$ & $121,0 \mathrm{aC}$ & $132,4 \mathrm{aA}$ & $127,4 \mathrm{abB}$ \\
202 & $114,2 \mathrm{bA}$ & $115,7 \mathrm{bA}$ & $115,4 \mathrm{bA}$ & $117,6 \mathrm{bB}$ & $125,1 \mathrm{dA}$ & $125,1 \mathrm{bcA}$ \\
211 & $115,8 \mathrm{abB}$ & $118,6 \mathrm{aA}$ & $116,2 \mathrm{abB}$ & $121,2 \mathrm{aB}$ & $129,4 \mathrm{bA}$ & $123,2 \mathrm{cdB}$ \\
225 & $116,4 \mathrm{aB}$ & $118,8 \mathrm{aA}$ & $117,4 \mathrm{aAB}$ & $121,3 \mathrm{aB}$ & $127,7 \mathrm{bcA}$ & $127,2 \mathrm{abA}$ \\
\hline
\end{tabular}

Letras minúsculas nas colunas e maiúsculas nas linhas não diferem estatisticamente entre si, pelo teste de Tukey, a 5\% de probabilidade.

TABELA 2- Soma térmica total (GD) dos clones de videira 'Concord' sobre três porta-enxertos, nas safras de 2009/2010 e 2010/2011. Rolândia-PR.

\begin{tabular}{ccccccc}
\hline & \multicolumn{3}{c}{ Safra 2009/2010 } & \multicolumn{3}{c}{ Safra 2010/2011 } \\
\cline { 2 - 7 } Clones de Concord & $420-\mathrm{A}$ & IAC 572 & IAC 766 & $420-\mathrm{A}$ & IAC 572 & IAC 766 \\
\hline 22 & $1521 \mathrm{aB}$ & $1570 \mathrm{aA}$ & $1549 \mathrm{abA}$ & $1499 \mathrm{aC}$ & $1546 \mathrm{cdB}$ & $1570 \mathrm{aA}$ \\
28 & $1519 \mathrm{aB}$ & $1575 \mathrm{aA}$ & $1552 \mathrm{aA}$ & $1472 \mathrm{bB}$ & $1552 \mathrm{cdA}$ & $1558 \mathrm{aA}$ \\
49 & $1525 \mathrm{aB}$ & $1570 \mathrm{aA}$ & $1555 \mathrm{aA}$ & $1472 \mathrm{bC}$ & $1627 \mathrm{aA}$ & $1555 \mathrm{aB}$ \\
202 & $1511 \mathrm{aA}$ & $1521 \mathrm{bA}$ & $1516 \mathrm{bA}$ & $1441 \mathrm{cC}$ & $1530 \mathrm{~dB}$ & $1555 \mathrm{aA}$ \\
211 & $1516 \mathrm{aB}$ & $1564 \mathrm{aA}$ & $1529 \mathrm{abB}$ & $1472 \mathrm{bB}$ & $1584 \mathrm{bA}$ & $1489 \mathrm{bB}$ \\
225 & $1531 \mathrm{aA}$ & $1543 \mathrm{abA}$ & $1540 \mathrm{abA}$ & $1472 \mathrm{bB}$ & $1570 \mathrm{bcA}$ & $1558 \mathrm{aA}$ \\
\hline
\end{tabular}

Letras minúsculas nas colunas e maiúsculas nas linhas não diferem estatisticamente entre si, pelo teste de Tukey, a $5 \%$ de probabilidade.

TABELA 3- Taxas médias de acúmulo de SS $\left({ }^{\circ}\right.$ Brix.dia $\left.{ }^{-1}\right)$ durante a evolução da maturação dos clones de videira 'Concord' sobre três porta-enxertos, nas safras de 2009/2010 e 2010/2011. Rolândia-PR.

\begin{tabular}{ccc}
\hline Clones de 'Concord' & $\begin{array}{c}\text { Taxas médias de acúmulo de SS }\left({ }^{\circ} \text { Brix.dia }^{-1}\right) \\
2009 / 2010\end{array}$ & $2010 / 2011$ \\
\hline 22 & $0,272 \mathrm{~b}$ & $0,245 \mathrm{~b}$ \\
28 & $0,290 \mathrm{ab}$ & $0,251 \mathrm{ab}$ \\
49 & $0,276 \mathrm{ab}$ & $0,243 \mathrm{~b}$ \\
202 & $0,314 \mathrm{a}$ & $0,289 \mathrm{a}$ \\
211 & $0,305 \mathrm{ab}$ & $0,270 \mathrm{ab}$ \\
225 & $0,305 \mathrm{ab}$ & $0,262 \mathrm{ab}$ \\
\hline F & $13,14^{*}$ & $3,39^{*}$ \\
\hline Porta-enxertos & & \\
$420-\mathrm{A}$ & $0,344 \mathrm{a}$ & $0,297 \mathrm{a}$ \\
IAC 572 & $0,247 \mathrm{c}$ & $0,233 \mathrm{~b}$ \\
IAC 766 & $0,287 \mathrm{~b}$ & $0,249 \mathrm{~b}$ \\
F & $51,08^{*}$ & $25,74^{*}$ \\
F (interação) & $1,54^{\text {ns }}$ & $1,35^{\mathrm{ns}}$ \\
\hline CV (\%) & 12,30 & 13,27 \\
\hline
\end{tabular}

Médias seguidas da mesma letra nas colunas não diferem entre si, pelo teste de Tukey $(\mathrm{P}<0,05) .{ }^{\text {ns }}$ não significativo, * significativo $(\mathrm{P}<0,05)$. 

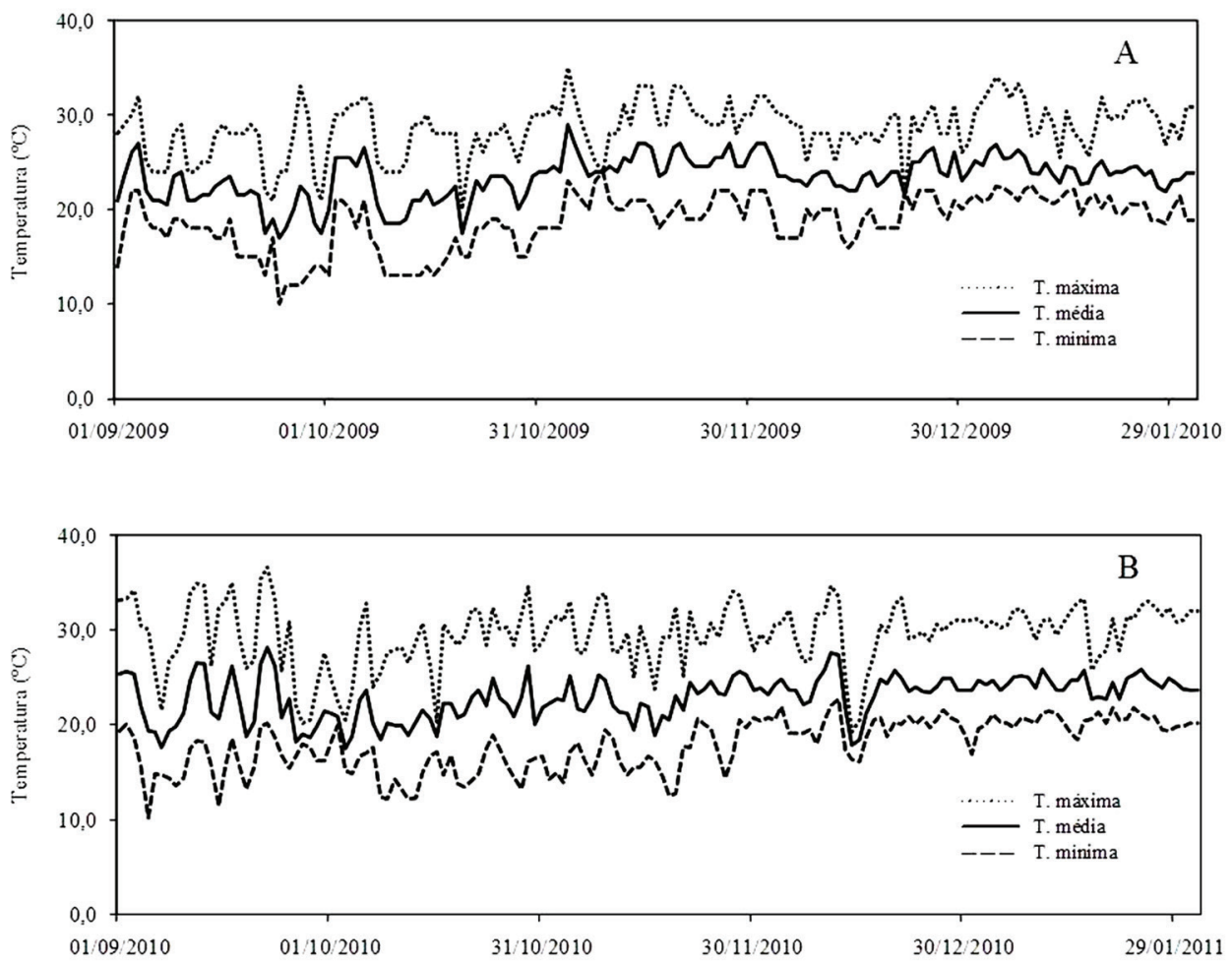

FIGURA 1- Temperaturas $\left({ }^{\circ} \mathrm{C}\right)$ máximas, médias e mínimas diárias da região de Rolândia-PR, durante as safras de 2009/2010 (A) e 2010/2011 (B). Fonte: Instituto Agronômico do Paraná - IAPAR.
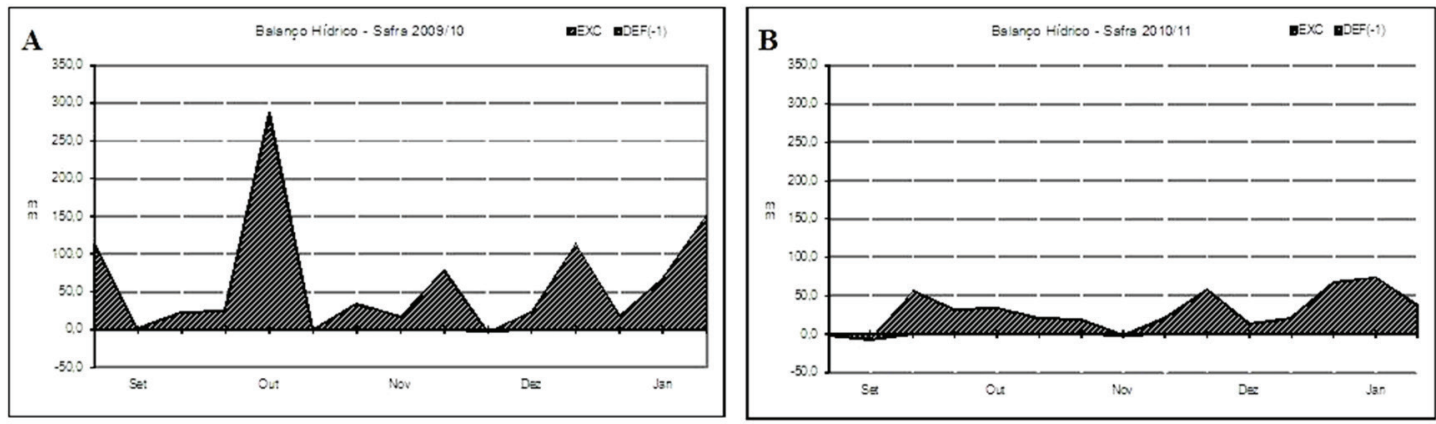

FIGURA 2- Balanço hídrico da região de Rolândia-PR, durante as safras de 2009/2010 (A) e 2010/2011 (B). Fonte: Instituto Agronômico do Paraná - IAPAR. 


\section{CONCLUSÕES}

Dentre os clones de 'Concord' avaliados, o '202' apresenta a menor duração do ciclo entre a poda e a colheita, sendo portanto o mais precoce. Dentre os porta-enxertos, o '420-A' induz a maior taxa de acúmulo diário de SS do mosto, proporcionando redução do ciclo de produção e da demanda térmica dos clones de 'Concord', enquanto o 'IAC 572' induz a menor taxa, promovendo aumento do ciclo e da demanda térmica dos clones.

\section{AGRADECIMENTOS}

À Corol Cooperativa Agroindustrial, à Universidade Estadual de Londrina, à Empresa Brasileira de Pesquisa Agropecuária, ao Conselho Nacional de Desenvolvimento Científico e Tecnológico e aos colegas dos Departamentos de Agronomia e Ciência e Tecnologia de Alimentos da UEL.

\section{REFERÊNCIAS}

ANZANELLO, R.; SOUZA, P. V. D.; CASAMALI, B. Fenologia, exigência térmica e produtividade de videiras 'Niagara Branca', 'Niagara Rosada 'e 'Concord' submetidas a duas safras por ciclo vegetativo. Revista Brasileira de Fruticultura, Jaboticabal, v.34, n.2, p.366-376, 2012.

ANZANELLO, R.; SOUZA, P. V. D.; GONZATTO, M. P. Produção de videiras 'Niagara Branca' e 'Concord' submetidas a duas safras por ciclo vegetativo na depressão central do Rio Grande do Sul. Scientia Agraria, Curitiba, v.9, n.3, p.311-316, 2008.

BORGES, R. S. ; SILVA, G. A. ; ROBERTO, S. R. ; ASSIS, A. M. ; YAMAMOTO, L. Y. Phenolic compounds, favorable oxi-redox activity and juice color of 'Concord' grapevine clones. Scientia Horticulturae, Amsterdam, v.161, p.188-192, 2013.

BRIGHENTI, A. F.; BRIGHENTI, E.; BONIN, V. ; RUFATO, L. Caracterização fenológica e exigência térmica de diferentes variedades de uvas viníferas em São Joaquim, Santa Catarina - Brasil. Ciência Rural, Santa Maria, v.43, n.7, p.1162-1167, 2013.

CAMARGO, U. A.; KUHN, G. B.; CZERMAISNKI, A. B. C. Concord clone 30. Uva precoce para suco. In: CONGRESSO BRASILEIRO DE FRUTICULTURA, 16., 2000, Fortaleza. Anais... Fortaleza: Embrapa Agroindústria Tropical/SBF, 2000. p. 621.
DIAS, F. A. N.; MOTA, R. V.; FÁVERO, A. C.; PURGATTO, E.; SHIGA, T. M.; SOUZA, C. R.; PIMENTEL, R. M. A.; REGINA, M. A. Videira 'Syrah' sobre diferentes porta-enxertos em ciclo de inverno no sul de Minas Gerais. Pesquisa Agropecuária Brasileira, Brasília, v.47, n.2, p.208215, 2012.

EMBRAPA - Empresa Brasileira de Pesquisa Agropecuária. Sistema brasileiro de classificação de solos. Rio de Janeiro: Centro Nacional de Pesquisa de Solos, 1999. 412p.

JOGAIAH, S. ; OULKAR, D. P. ; BANERJEE, K. ; SHARMA, J.; PATIL, A. G. ; MASKE, S. R. ; SOMKUWAR, R. G. Biochemically Induced Variations During Some Phenological Stages in Thompson Seedless Grapevines Grafted on Different Rootstocks. South African Journal for Enology and Viticulture, Dennesig, v.34, n.1, p.36-45, 2013.

MANDELLI, F.; BERLATTO, M. A.; TONIETTO, J.; BERGAMASCHI, H. Fenologia da videira na Serra Gaúcha. Pesquisa Agropecuária Gaúcha, Porto Alegre, v.9, n.1-2, p.129-144, 2003.

PEDRO JÚNIOR, M. J.; SENTELHAS, P. C. Clima e produção. In: POMMER, C. V. Uva: tecnologia de produção, pós-colheita, mercado. Porto Alegre: Cinco Continentes, 2003. p.63-107.

PEREIRA, G. E. ; LIMA, L. C. O. ; REGINA, M. A.; ROSIER, J. P.; FERRAZ, V.; MOURÃO, J. M. Avaliação do potencial de cinco cultivares de videiras americanas para sucos de uva no sul de Minas Gerais. Ciência e Agrotecnologia, Lavras, v.32, n.5, p.15311537, 2008.

PEZZOPANE, J. R. M.; PEDRO JÚNIOR, M. J.; CAMARGO, M. B. P.; FAZUOLI, L. C. Exigência térmica do café arábica cv. Mundo Novo no subperíodo florescimento-colheita. Ciência e Agrotecnologia, Lavras, v.32, n.6, p.1781-1786, 2008.

REGINA, M. A. Analise comparativa da organização e metodologia da seleção clonal da videira na França e Brasil. Ciência e Agrotecnologia, Lavras, v.28, n.1, p.206-212, 2004.

RIZZON, L. A.; MIELE, A. Analytical characteristics and discrimination of Brazilian commercial grape juice, nectar, and beverage. Ciência e Tecnologia de Alimentos, Campinas, v.32, n.1, p.93-97, 2012. 
ROBERTO, S. R. ; SATO, A. J. ; BRENNER, E. A. ; SANTOS, C. E. ; GENTA, W. Fenologia e soma térmica (graus-dia) para a videira 'Isabel' (Vitis labrusca) cultivada no noroeste do Paraná. Semina : Ciências Agrárias, Londrina, v.25, n.4, p.273-280, 2004.

SATO, A. J.; JUBILEU, B. S.; SANTOS, C. E.dos; BERTOLUCCI, R.; SANTOS, R.dos; CARIELO, M.; GUIRAUD, M. C.; FONSECA, I. C. B.; ROBERTO, S. R. Fenologia e demanda térmica das videiras Isabel e Rubea sobre diferentes porta-enxertos na região norte do Paraná. Semina: Ciências Agrárias, Londrina, v.29, n.2, p.283-292, 2008.
TECCHIO, M. A. ; MOURA, M. F. ; PAIOLI-PIRES, E. J. ; TERRA, M. M. Efeito do porta-enxerto e da época de poda na duração das fases fenológicas e no acúmulo de graus-dia pela videira 'Niagara Rosada. Revista Brasileira de Fruticultura, Jaboticabal, v.35, n.4, p.1073-1080, 2013.

VILLA NOVA, N. A. Estimativa de graus-dia acumulados acima de qualquer temperatura- base em função das temperaturas máxima e mínima. Ciência da Terra, São Paulo, n.30, p.1- 8, 1972. 